\title{
Peer feedback for peer learning and sharing
}

\author{
Fawzi Al-Ghazali
}

Abu Dhabi University, UAE

\begin{abstract}
Peer feedback is applauded in many writing courses for fostering students' independence and collaboration and for creating a wider learning environment in which students can benefit from the feedback and diversity of input they get from other peers (Stubbe, 2013). It improves students' writing skills by developing their use of effective composing processes since they can share ideas while planning, drafting, and revising writing forms (Richards and Schmidt, 2010). It also reduces the anxiety of students who can get constructive feedback on their writing from other peers instead of their teachers (Phillipson, 2007). However, application of peer feedback in writing courses is a complex process since it requires provision of rubrics and guidelines for students to follow; this is in addition to explaining the areas they need to focus on. It also requires having cultural awareness of the level of corrections Arab students can accept. This paper reflects on a practical experiment conducted with a group of undergraduate students for showing how peer feedback is approached and practised by students in English language courses. Students' views and perceptions about peer feedback are also surveyed showing their appreciation of the level of collaboration peer feedback encourages among them. Nevertheless, the results also show a number of concerns students have about peer feedback.
\end{abstract}

\section{Introduction}

The extensive research studies done by researchers like Charoenchang, 2013; Liu and Hansen 2002; Lundstrom and Baker, 2009; Paulus,1999; Porto, 2001; Stubbe, 2013; and Yang et al, 2006 on Peer Feedback (PF) indicate the significance this innovation is garnering in EFL learning contexts. They show that student collaboration in the learning process fosters self-directed learning and autonomy. These studies investigate students' beliefs and teachers' perceptions of PF within specific contexts. The awareness of the role of the social context in belief research (Holliday, 2005) encouraged similar studies in various Arab settings that examine students' beliefs about PF. For instance, Azaza (2013) conducted an action research in the UAE for understanding how PF improves the writing mechanics of students at the school level. Aloud (2013) in Saudi Arabia also applied a study technique with a group of undergraduate students to identify the effectiveness of online PF in enhancing their writing skills.

Within the UAE context, this study explores how PF is practised by 150 undergraduate students at Abu Dhabi University. It investigates their attitudes towards the PF technique and how it enhances their technical writing skills. A three-stage process is applied including presenting samples of edited work to clarify the duties of both producers and recipients of the edits. Samples of students' edited work are analysed to evaluate the quality, quantity, and abundance of peer input. In addition, students' beliefs are surveyed and the statistical and thematic analyses reveal a set of internal and external factors that affect how students practise PF. As articulated by Tang and Tithecott (1999), improving the writing competence of students is not easily achieved, and PF is considered one of the several techniques to do so. Hence, the findings of this study provide insights into how PF could be reinforced at the university level in the UAE. 


\section{Literature review}

PF is considered by Chong (2010: 53) as a form of "collaborative writing approach" in which students benefit from the feedback and the diversity of input of their peers. Richards and Schmidt (2010) view it as the counterpart of peer review and peer response in which students receive feedback on their writing from peers. Charoenchang (2013) considers these terms as similar in the process of implementation since they serve as a means to promote independent writing. In addition, Liu and Hansen (2002) argue that $P F$ refers to the

use of learners as sources of information, and interactants for each other in such a way that learners assume roles and responsibilities normally taken on by a formally trained teacher, tutor, or editor in commenting on and critiquing each other's drafts in both written and oral formats in the process of writing. (p. 1)

Students can, for example, see how to draft a topic sentence when they see how it is written by fellow students. PF therefore fosters student collaboration, which in turn enables them to construct and share knowledge (von Glasersfeld, 2005). Charoenchang (2013: 3) also believes that PF "brings about more classroom interaction as learners ask, explain and give comments to each other. Such interactions help to enhance their learning because in doing so, both writers and editors focus on meaning as well as form of language". Von Glasersfeld (2005) finds that boosting student independence and interdependence underlies a constructivist ontology which appreciates student agency in language classes and encourages their cooperation with others for constructing knowledge. Knowledge is being viewed as the "outcome of experience mediated by one's own prior knowledge and the experience of others" (Philips, 2003: 232). One way of enhancing student independence and autonomy is PF. It is praised for reducing student reliance on language teachers and for creating a wider learning environment in which students benefit from the feedback and diversity of input produced by peers (Stubbe, 2013).

PE has been proposed as a valuable technique in academic and technical writing courses. Richards and Schmidt (2010) consider it a form of the writing process approach which relies on the gradual and independent improvement of writing skills. Chong (2010: 55) calls it a small portion of the writing process approach. It enhances student composition processes and allows them to share ideas while planning, drafting, and revising writing forms. It enables students of low linguistic ability to benefit from the experience and feedback of higher achieving students. As a means of providing constructive critique on written work, PF not only benefits recipients of the edits, but also the editors themselves who acquire the skill to assess and provide justifiable comments (Stubbe, 2013). Phillipson (2007), in addition, finds that PF widens the scope and thinking patterns of students when they compose a piece of writing. It encourages them to write for a broader audience, such as peers, rather than simply writing directly for their direct teachers. This entails using a readable style in terms of clarity, directness, and conciseness that can be understood by students of different linguistic levels (Houp et al, 2009).

For Charoenchang (2013), PF promotes student awareness of metacognitive strategies and enhances self-reliance. Acquisition of these strategies fosters autonomy and enables them to identify how to plan, monitor, and evaluate their learning (Wenden, 1999). It enables low achieving students to scaffold new concepts and associate existing knowledge with new input in situations when they are guided by higher achieving students to fix existing errors. It reduces student anxiety and creates a less threatening learning atmosphere simply because any common flaws in students' written work will indicate a shared gap in their understanding rather than an individual weakness (Rollinson, 2005).

PF nevertheless has some pitfalls outlined by Phillipson (2007). Unless the aspects of PF are explicitly signalled from the beginning, students may focus on the relatively trivial emendations like spelling and 
grammar deformations and neglect the overall content and organisation of a document. Awareness of the perspectives of PF not only permits givers of the edits to provide comprehensive evaluation of a document, but also enables receivers of the edits to evaluate the levels of input they receive from their partners. Occasionally, misinterpretation of an editor's feedback exists particularly when he suggests a correction that may weaken a paper. Hence, students should neither be highly defensive nor overly tolerant in accepting the feedback suggested by peers (Phillipson, 2007). One way to make student feedback more productive is to allow them to read samples of works reviewed by teachers or experienced students to identify how written work should be edited and the aspects they should monitor while reviewing.

Another drawback of PF is that some students are not competent enough to provide constructive feedback on the written work of their peers. Sometimes they are too awkward to provide valuable input that improves the original work of distinguished students. This issue is addressed in this study. Phillipson (2007), moreover, emphasises cultural constraints, considering them very effective while reviewing a peer's work. Some students are too polite to critique others' work unless some mistakes are prominent and correcting them will not embarrass the writer. Otherwise, they consider focusing on the flaws in others' works an offending act. These cultural traits are heavily embedded in Arab culture (Atkine, 2004). Atkine goes further as he postulates that the term "criticism" is not widely used in Arab culture and "when it is voiced, it is usually in terms of a condemnation of Arab acceptance of some aspect of Western culture" (ibid, 47). This argument suggests that many Arabs do not mind criticising some aspects of the Western culture that conflict with their local traditions rather than criticising each other's work. My current study aims to further that understanding and to explain the impact of the Arab culture on student practice and attitudes towards PF.

Among the studies that addressed PF in non-Arab contexts was that of Chong (2010) in Hong Kong, who concluded that some students explicitly supported PF; however, others were quite reserved, either due to the distrust in their abilities as editors, or distrust in the abilities of other students to guide and review their work. Another study for Stubbe (2013) at James Madison University in Virginia revealed that PF was not highly beneficial to students' writing due to a lack of student confidence in the process, thereby creating "going through the motions" (ibid, 3) types of corrections. These studies bolster the belief that PF becomes more favourable when students appreciate the bilateral cooperation and feedback of others. In Arab settings, it seems there is a lack of significant research addressing PF at both school and tertiary levels except for the two studies of Azaza and Aloud. Azaza (2013) conducted a study on PF with school students in the UAE. He concluded that PF improved the writing mechanics of students; however, he also found that PF alone remains insufficient unless complemented with teacher feedback and self-feedback. Another study, by Aloud (2013), with undergraduate students in Saudi Arabia revealed that online PF increased students' enthusiasm and collaboration and developed their writing abilities. In a rather different context, my current study aims at examining how PF is implemented, practised, and perceived by a group of undergraduate students at Abu Dhabi University in the UAE.

\section{Methodology}

\section{Participants}

This study was conducted with 150 undergraduate students in five sections at Abu Dhabi University in the academic year 2012-2013. They were enrolled in a variety of majors but had to study English for Business and Technical Communications writing course (ENG-201) as a part of the university requirements. The female participants made up $53 \%$ and the males made up $47 \%$ of the sample. They 
ranged in age from 18 to 22 , with a median age of 20 . The native language of $85 \%$ of the students was Arabic; however, $15 \%$ were Indians, Nigerians, and various European nationalities. Unlike academic writing courses, ENG-201 introduces students to the basic principles and skills necessary to construct technical and business letters, with emphasis on writing for the workplace. It also reinforces the basic research tools to help them prepare workplace documents and enhance their writing skills (Houp et al, 2009).

\section{Stages of implementing peer feedback}

Different approaches to conducting PF in language classes are suggested by researchers. For instance, Kroll (2001) argues that peer feedback can be expressed verbally through mutual discussion between the peer editor and partner or through producing written comments. The two modes can even be combined consecutively in which an oral discussion can follow suggested written corrections. I favoured combining both written and oral feedback to provide students with an opportunity to elaborate on the suggested corrections. This was implemented through a three-stage process which I call APT, standing for Awareness - Peer-feedback - Talk. The three APT stages were practised by students four times representing the number of assignments they did in class. Providing feedback on the hardcopies submitted by partner students was followed by close discussion for about ten to fifteen minutes between the editor and the composer of the written work. These three stages are interlinked and work in concordance with each other. Application of each stage facilitates the development of the other stages. For instance, the awareness stage aims at increasing student knowledge of what the feedback process includes and the level of input they anticipate from peers. It provides them with both theoretical and practical experience prior to getting engaged in the actual review process. It also enables students to comprehend and identify the main parts of a business letter (appendix one). This covers the "Opening" that explains the purpose, the "Focus" that provides enough details on the topic, the "Action" that states what the writer plans to do, and the "Closing" that shows the writer's positive attitude and strong rapport. This stage also involves providing samples of edited documents (appendix two) with minor changes and simple emendations. Other documents have major corrections related to the overall layout.

In the editing stage, both producers and receivers of the edits were encouraged to use pseudonyms to make their identities anonymous during the time of editing at least. This arrangement offers both sides greater freedom and reduces embarrassment that may arise as a result of the reciprocal editing process. The role of the instructor at this stage was to remind student editors to check for the content and organisation as well as superficial mistakes. In the post-editing stage, closed peer discussions were encouraged, in which students engaged in conversations discussing the editor's feedback and the writer's view. Open discussion was also conducted to clarify any controversial comments suggested by editors. The instructor's role meanwhile was to monitor discussions and intervene to verify or provoke discussion on corrections suggested by partner peers. The rationale of this activity was to allow the whole class students to identify the very common mistakes they had in their written work.

\section{Student questionnaire}

Administering the questionnaire was done after the students finished doing the regular course assignments and applied the three "APT" stages with the four assignments. This did not require formal ethical approval from the university since it falls within the learning process of the course. Students were not compelled to do the questionnaire; rather they found it opportunity to express their views on the merits and/or demerits of PF. The questionnaire used in this study (appendix three) consists of 
seven focused items; six of them are designed on the Likert-type template ranging from level five "strongly agree" to level one "strongly disagree" with level three "not sure". This format allows to answer research questions systematically and to examine student attitudes in a structured and disciplined way. This simple and reliable format gives participants the chance to shift smoothly from positive to negative and to choose the figure that most closely expresses their views. A final open-ended question "What other advantages / disadvantages of peer feedback do you see?" was added to allow students to reflect on the ideas they find relevant, yet were not covered in the other items of the scale. In order to check clarity of the questionnaire items, it was piloted with twenty students beforehand to modify any confusing words. This number was necessary to validate the questionnaire and verify its psychometric features in terms of the internal consistency and correlation between its items. An item analysis was also conducted, and the Cronbach's Alpha Coefficient was measured showing it was 79.3\%, a good ratio as argued by Dörnyei (2003):

Sometimes lower Cronbach Alpha coefficients are to be expected, but even with short scales of 3-4 items we should aim at reliability coefficients in excess of 0.70 ; if the Cronbach Alpha of a scale does not reach 0.60 , this should sound warning bells (Dörnyei, 2003: 112).

Based on student responses, factor analysis and descriptive statistics were applied to understand the trend of student attitudes in relation to this topic.

\section{Analysis of results}

\section{Peer feedback on students' written work}

In the technical writing course, students write technical documents like enquiry, reference, and condolence letters, etc. The analysis of their feedback shows different levels of input. As shown in the samples of appendix four, the editor of the enquiry letter (sample one) suggested minor corrections related to spelling and grammar mistakes. Some words were underlined for their incorrect spelling such as: "deffirant (different), inquaries (inquiries), peaces (pieces), notised (noticed), castomar (customer), convenice (convenience), clearify (clarify), and delevary (delivery)". This is in addition to picking out two grammar mistakes in which the copula "is" was replaced by "are". The editor did not provide feedback on the overall organisation of the letter, but it seems s/he was uncomfortable with the level of writing and hence graded the student with a score of three out of five. This form of input was selective rather than informative and did not provide sufficient hints and helpful suggestions on how the whole letter could be enriched and improved.

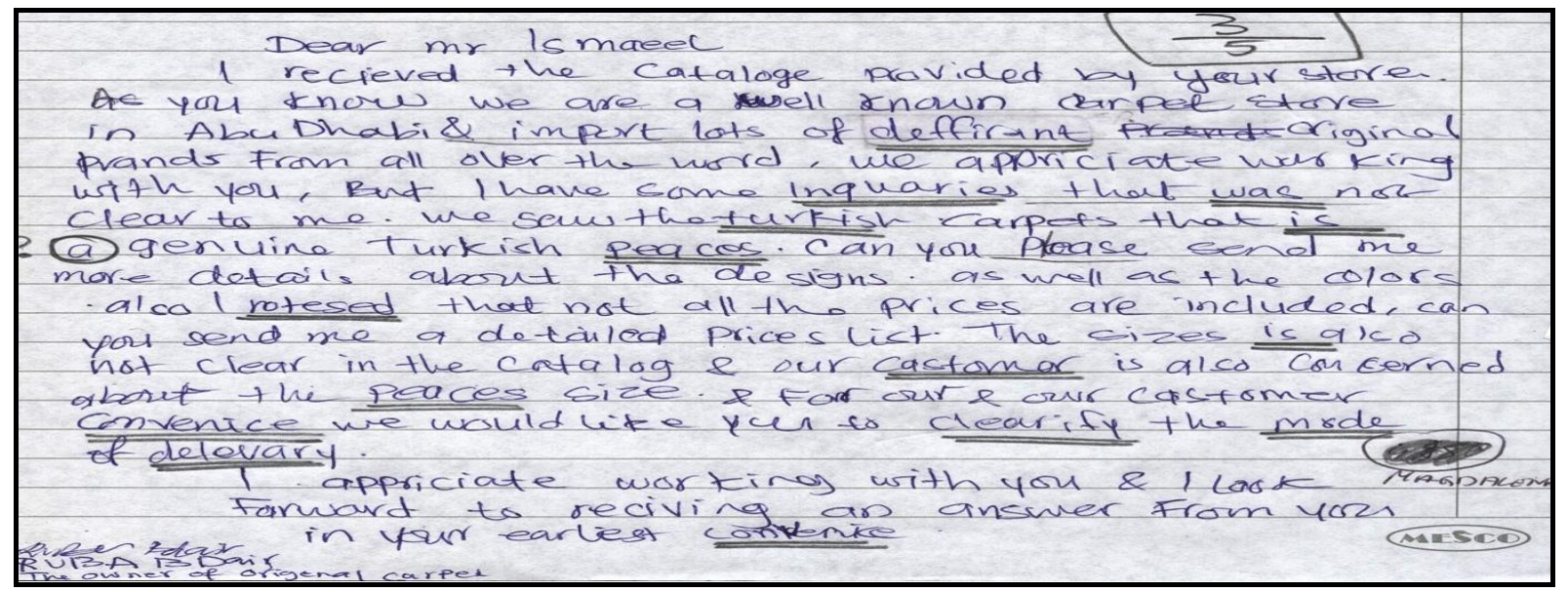

Figure 1: Sample writing (a).

Al-Ghazali, F. (2015). Peer feedback for peer learning and sharing. Learning and Teaching in Higher Education: 
In sample (b) Figure 2, the peer editor of this reference letter seems to have awareness of a range of aspects of the letter to be edited. For example, as well as highlighting some spelling errors like duuities (duties), assiting (assisting), efficienict (efficient), and postion (position), $\mathrm{s} / \mathrm{he}$ also reflected on the basic parts of the letter, for example using the fixed expression "To whom it may concern" instead of "Dear Mr. ..." since a reference letter is often sent to someone unknown to the referee. In addition, s/he considered that more details should be added about the previous responsibilities and current qualities of the candidate. This detailed input indicates awareness of English language structures. Syntactic changes were not the only suggestions of this peer editor: $\mathrm{s} /$ he recommended adding the clause "Do not hesitate to contact me for any further information" so as to guide the student writer in concluding the letter. S/he showed the student writer how to end a formal letter by using the term "Sincerely" instead of "Yours" followed by the name of the addressor and his/her position. Such detailed feedback suggests that the linguistic level of this editor played a part in the editing process in terms of quality and quantity of the input given as discussed above in the literature review.

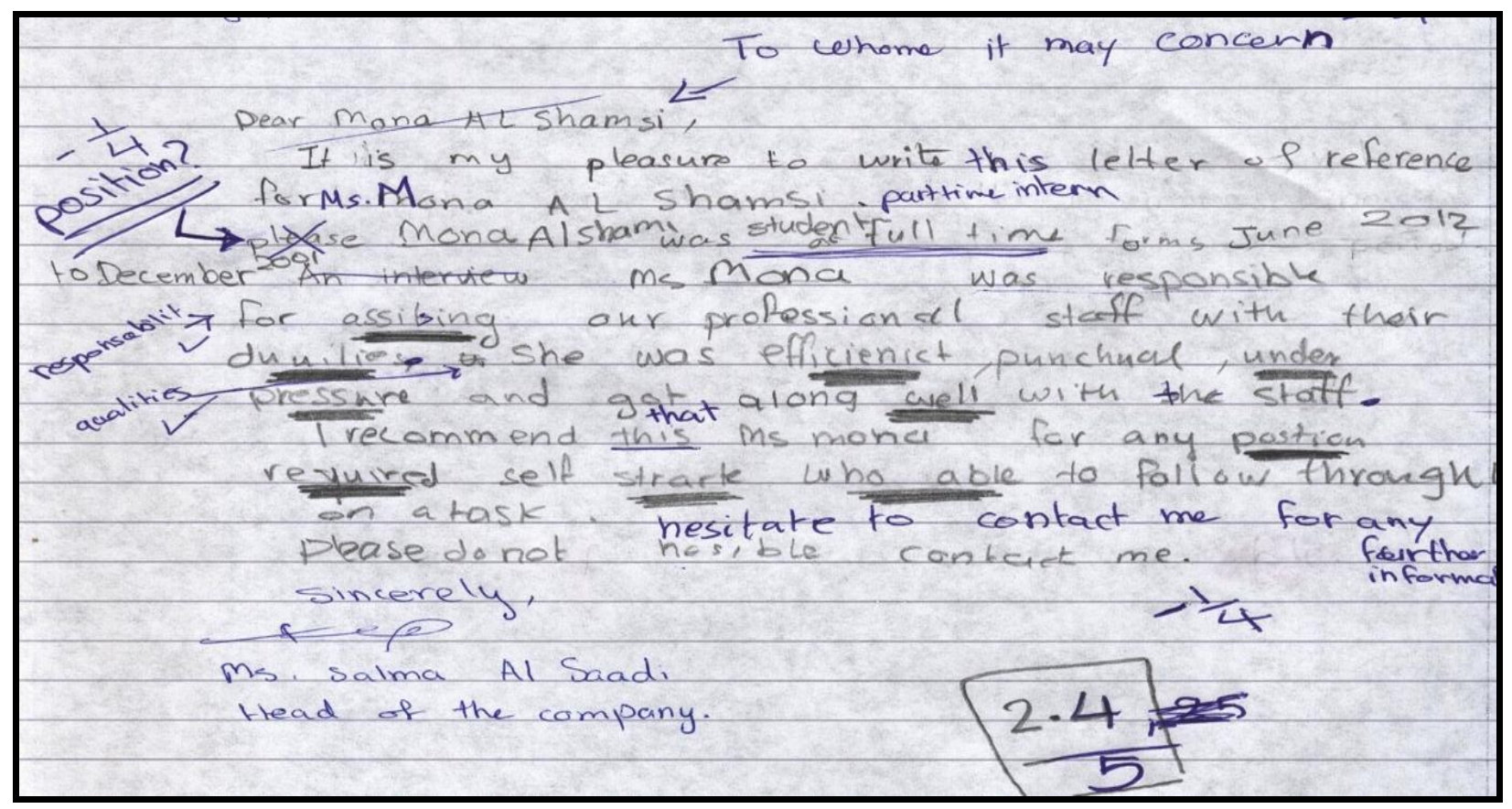

Figure 2: Sample writing (b).

The reflection on the third sample letter was limited to showing sentences had missing verbs, misspelled words, or poor sentence structure. No detailed corrections were offered and the feedback was limited to symbols like "V (verb), Sp (spelling), St (structure), etc. Students found this level of input insufficient since it does not guide them to improve their written texts and it needs skills for decoding these abbreviations. 


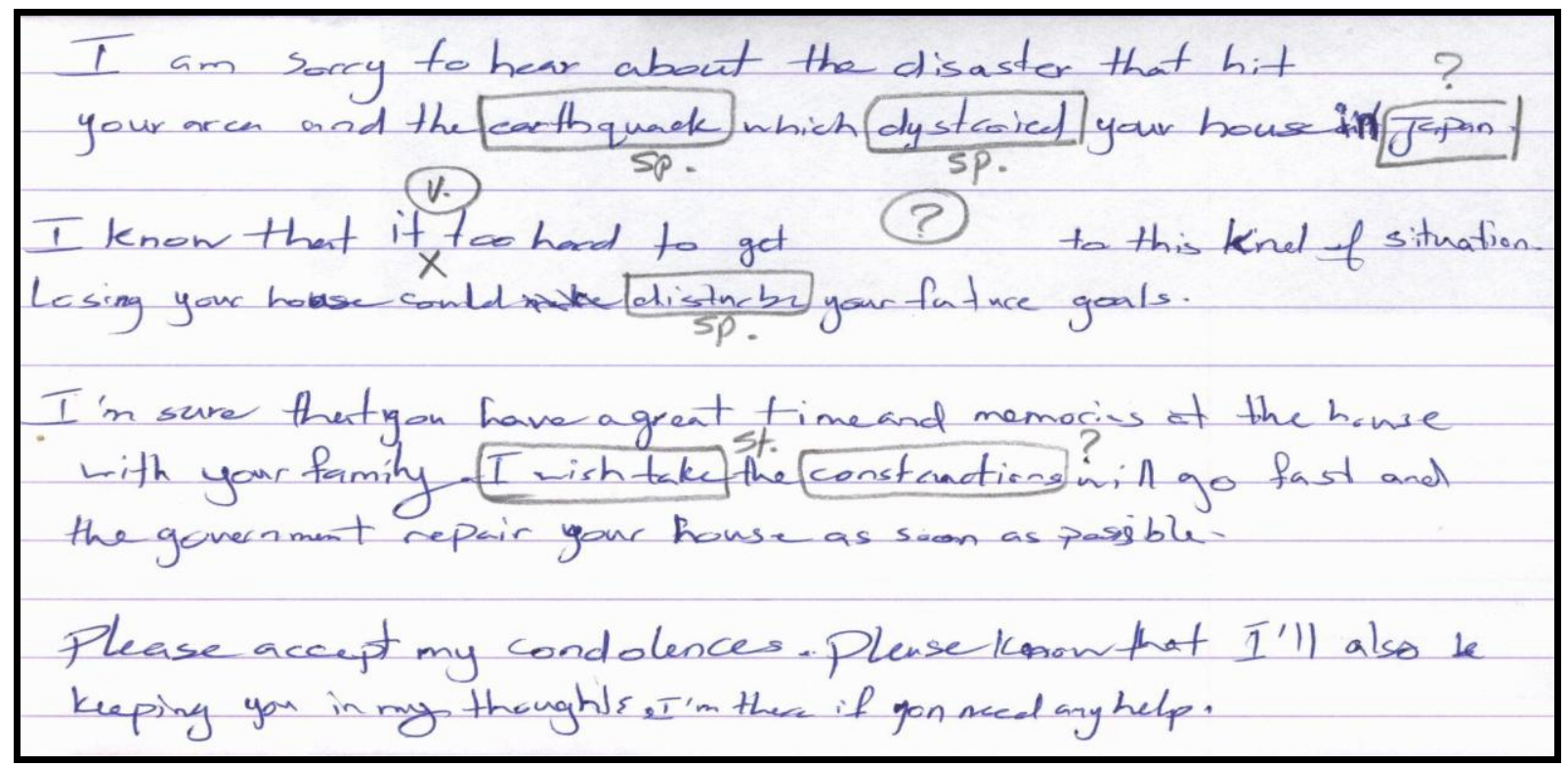

Figure 3: Sample writing (c).

Notably, the abridged responses of some editors could be attributed to lack of linguistic and academic writing abilities. Another possibility is that they are inexperienced in other areas of feedback needed to properly examine the sample writings of peers. Hence, their feedback becomes limited to checking for simple errors.

\section{Factor analysis and descriptive statistics}

Students' responses on the questionnaire items were analysed statistically using factor analysis to identify the clusters of attitudes students hold about PF. Descriptive statistics were also calculated to discern the trend of students' attitudes and conceptions of PF and to recognise the frequency of their responses in terms of the mean and standard deviation of each item. As shown in Error! Reference source not found. below, factor analysis of the questionnaire responses resulted in two factors whose eigenvalues were greater than 1 and which accounted for $68.87 \%$ of the total variance of the scale. The high eigenvalue of factor 1 relative to factor 2 indicated the significance of the former over the latter. This analysis showed that factor 1 explained $49.61 \%$ of the total variance whereas the second factor accounted for $19.26 \%$ of the variance. This may well be due to the number of items loaded on each factor. As illustrated in Error! Reference source not found., factor 1 was loaded on four items in the questionnaire which deal with the mechanics of PF and what students actually do or need to know before being engaged in the process of editing. Conversely, factor 2 was loaded on two items related to more personality related aspects of PF.

Table 1: Extracted factors and their variance

\begin{tabular}{|l|l|l|l|l|}
\hline Factor & Description & Eigenvalue & \% of Variance & Cumulative \% \\
\hline 1 & Mechanics of peer feedback & 2.977 & 49.611 & 49.611 \\
\hline 2 & Personality outcomes of peer feedback & 1.156 & 19.258 & 68.869 \\
\hline
\end{tabular}


Table 2: Rotated factor loadings of students' responses

\begin{tabular}{|c|l|c|c|}
\hline Item & Description & F1 & F2 \\
\hline Factor 1: Mechanics of Peer Feedback & 0.788 & \\
\hline 5 & My feedback varies based on my interest and familiarity with the topic. & 0.782 & 0.763 \\
\hline 3 & While reviewing, I focus on surface spelling and grammar mistakes. & 0.720 & \\
\hline 4 & The teacher should provide rubrics to follow before reviewing any writing. & & 0.633 \\
\hline 1 & I think peer feedback is helpful for improving my writing skill. & & 0.494 \\
\hline Factor 2: Personality Outcomes of Peer Feedback & Peer feedback enhances my independence, autonomy, and self-confidence. & & \\
\hline 6 & I trust the feedback I get from other classmates. & & 0.79 \\
\hline 2
\end{tabular}

Error! Reference source not found. shows the frequencies of students' responses showed that the average Mean of students' responses was 3.90, indicating that in general respondents agreed with statements in the questionnaire. Similarly, the frequencies of responses were distributed as $32.5 \%$ for "strongly agree", 39.5\% for "agree", 18.5\% for "not sure", $4.5 \%$ for "disagree", and $4 \%$ for "strongly disagree". While these figures can be used as indicators of students' familiarity with PF, their responses on the open-ended question also provided insights into how they perceived and approached this technique as explained in more detail below.

Table 3: Item analysis and frequencies of students' responses

\begin{tabular}{|c|c|c|c|c|c|c|c|c|c|}
\hline \multirow[b]{2}{*}{ Item } & \multirow[b]{2}{*}{$\mathbf{N}$} & \multirow[b]{2}{*}{ Mean } & \multirow[b]{2}{*}{ SD } & \multirow[b]{2}{*}{$\alpha$} & \multicolumn{5}{|c|}{ Frequencies } \\
\hline & & & & & $\begin{array}{l}\text { Strongly } \\
\text { Agree }\end{array}$ & Agree & Not Sure & Disagree & $\begin{array}{l}\text { Strongly } \\
\text { Disagree }\end{array}$ \\
\hline Q1 & \multirow{7}{*}{150} & 4.21 & 1.012 & \multirow{7}{*}{$79.3 \%$} & $43.3 \%$ & $48.7 \%$ & $0 \%$ & $4 \%$ & $4 \%$ \\
\hline Q2 & & 3.41 & 1.063 & & $16 \%$ & $27.3 \%$ & $48.7 \%$ & $0 \%$ & $8 \%$ \\
\hline Q3 & & 3.66 & 1.163 & & $20 \%$ & $52 \%$ & $12 \%$ & $8 \%$ & $8 \%$ \\
\hline Q4 & & 4.41 & .837 & & $60 \%$ & $24 \%$ & $16 \%$ & $0 \%$ & $0 \%$ \\
\hline Q5 & & 3.55 & 1.097 & & $16 \%$ & $48.7 \%$ & $16 \%$ & $15.3 \%$ & $4 \%$ \\
\hline Q6 & & 4.17 & .825 & & $41 \%$ & $39 \%$ & $20 \%$ & $0 \%$ & $0 \%$ \\
\hline Mean & & 3.90 & 0.706 & & $32.7 \%$ & $40 \%$ & $18.8 \%$ & $4.5 \%$ & $4 \%$ \\
\hline
\end{tabular}

Mechanics of peer feedback

This factor was loaded on four items which represented different attitudes about the mechanics of PF and what makes this process more useful. The analysis showed that the loadings of these items were high and the difference between the highest and lowest loaded items was not great. These items contributed much to the variance of the scale and it seems they were the items best related to students' view of PF. Starting with the general beliefs of students; the loading of item one "I think peer feedback is helpful for improving my writing skill" was 0.720 with an average Mean of 4.21 . This item had a high percentage of agreement among students with $43.3 \%$ who strongly agree and $48.7 \%$ who agree in contrast with $4 \%$ who disagree and the same percentage for those who strongly disagree. The response 
to this item could be indicator of students' appreciation of PF and the feedback they get from other peers. The loading of item four "The teacher should provide rubrics to follow before reviewing any writing" was 0.763 with an average Mean of 4.41 . This item had the highest percentage of the students who strongly agree (60\%) in addition to $24 \%$ who agree, $16 \%$ who are not sure, and with $0 \%$ opponents to it. This obvious agreement makes the necessity to state the guidelines and rubrics of feedback in advance more crucial.

Item five "My feedback varies based on my interest and familiarity with the topic" was loaded highly on this factor (0.788) with an average Mean of 3.55. The percentages of students' responses were $16 \%$ for strongly agree, $48.7 \%$ for agree, $16 \%$ for not sure, $15.3 \%$ for disagree and $4 \%$ for strongly disagree. Moreover, the loading of item three "As a peer editor, I focus on surface errors like spelling and grammar mistakes" was 0.782 with an average Mean of 3.66. The frequency of responses revealed that more than half of the students (52\%) agree with it in addition to $20 \%$ who strongly agree. This is in comparison with $12 \%$ for not sure, $8 \%$ for disagree and the same percentage for strongly disagree. In addition to the statistics above, the factor analysis shows the differences among students. It signifies that students who focus on surface errors feel that PF is helpful; while students who focus on the overall content and organisation in addition to the surface errors feel that PF is less helpful for improving the internal structure of a written work.

\section{Personality outcomes of peer feedback}

This factor was loaded on two items representing students' attitudes on the personality and affective outcomes of PF. The loading of item six was greater than the loading of item two, indicating the contribution of the former item was adding to the variance of the scale. The statistics given in tables two and three showed that the loading of item six "Peer feedback enhances my independence, autonomy, and self-confidence" was 0.633 with a Mean of 4.17. The analysis of students' responses showed no opponents to this item with $41 \%$ for those who strongly agree, $39 \%$ for those who agree, and $20 \%$ for those who are not sure. About $80 \%$ of students therefore agree that PF enhances their independence and self-confidence and reduces their reliance on teachers. Their autonomy develops the more they acquire the missing knowledge they need to compensate from more knowledgeable peers. This attitude was not identical to the other item loaded on the same factor. Item two "I trust the feedback I get from other classmates" was loaded at level 0.494 with a Mean of 3.41. The analysis shows that almost half of the students (48.7\%) were not sure about their attitudes if they trusted the feedback they get from other peers in contrast to $16 \%$ who strongly agree with this item and $27.3 \%$ who agree. Students view the feedback of their peers from different perspectives, and their appreciation of peer input varies based on the general achievement of those peers on the course at large. The two items of this factor signal the constructivist role of PF in enhancing student ability to plan, monitor, and evaluate their written work.

\section{Open-ended question}

The question "What other advantages/ disadvantages of peer editing do you see?" encouraged students to reflect on areas pertaining to PE not covered in the other items. Besides the different beliefs students revealed, the thematic analysis of responses signalled four themes relating to advantages of $P E$ and two more themes related to its disadvantages. Discussing each theme is supported here with quotes from students' comments, followed by the student's pseudonym, which includes $\mathrm{M}$ to indicate a male student and $\mathrm{F}$ a female. 


\section{Theme 1: PF benefits the giver and receiver of the edits}

This theme expresses student beliefs about the positive impacts of PF on increasing their awareness of the mistakes they make when producing any piece of writing. Some of the students' contributions were "When I edit any work, I learn not to repeat the same mistakes in my writing (F-17)", "Peer feedback allows me to learn from others' mistakes (M-8)", and "Peer feedback allows me to see the writing structures of classmates (F-48)". Notably, most of the students who commented mentioned this. They find picking up the mistakes in other students' work easier than identifying their own mistakes. Taking the position of an editor sometimes frees them from the overall burden of arranging ideas or selecting the appropriate lexical items and sentence structures. The benefits of PF are accordingly reciprocal and shared by both the giver and receiver of the edits. Such a belief is reinforced in a similar study conducted by Lundstrom and Baker (2009). They found that the benefits of peer review to the reviewers' own writing were very great and that the givers of the edits at the lower proficiency level "made more gains than those at the higher proficiency levels" (ibid, 30).

\section{Theme 2: PF improves the fluency and accuracy of students' language}

This theme signals the contributions PF had for improving students' spoken English. Most of the answers were ones such as "Peer feedback opens the door for more conversation (M-5)", "Peer feedback helps me to be a good listener as well (M-36)", and "Peer feedback encourages me to speak and critique the work of other students (F-41)". Students find pair discussions opportunity to understand concepts and acquire new ideas from peers that can hardly be acquired through brief written feedback. In addition, they reported that PF had positive impacts on improving their writing at large. Examples of their responses were "Peer feedback allows me to get some feedback on my writing (M-29)", "Peer feedback shapes my writing skills (F-19)", and "Peer feedback enables me to evaluate my writing (F-27)". Although students produce less detailed feedback as explained above, their input seems valuable since it provides insights into how writers can improve the mechanics of their writing through the diversity of input they receive from peers.

\section{Theme 3: PF encourages classroom communication}

This theme shows student appreciation of PF for enhancing classroom communication. It encourages them to exchange ideas on academic issues at least. Samples of the comments were "Peer feedback helps me to make new friends and maintain a strong rapport with other classmates (F-35)" and "Peer feedback encourages me to communicate with other classmates (M-17)". This could be considered a positive side of PF since it promotes student collaboration and sharing of ideas. While reviewing students' written work is the primary objective for initialising PF, other benefits can be gained, for instance in fostering student discussion and presentation skills.

\section{Theme 4: PF enhances students' confidence and independence}

This theme signifies the affective side of PF, embodied in the enhancement of student confidence and independence. Some of the responses were "Peer feedback builds up self-confidence (M-45)" and "Peer feedback enhances my independence from instructors (F-2)". Students find peer interaction one way to reduce their reliance on instructors and to build up knowledge through discussion and interaction with peers.

These four themes demonstrate student beliefs about the PF innovation which provides them with an alternative means of learning not necessarily via teacher input. Low achieving students benefit from the linguistic input of high achieving students in improving their writing skills. However, students reported disadvantages of PF listed under the following two themes. 


\section{Theme 5: accurate feedback is not guaranteed}

A few of the students who commented considered that the PF type was not always trustworthy. Some of their responses were "Some of the information I get might not be 100\% correct (F-30)", "Some students do not learn from their mistakes because they are not sure whether the feedback they get is correct (M-7)", and "I trust the feedback I get from instructors more than my peers (M-24)". This belief exists among a few students either because they were not competent enough to evaluate the accuracy and relevance of PF or because this is an embedded feature of their culture that ranks the position of a teacher, as well as his recommendations and directions, highly.

\section{Theme 6: PF creates an unfriendly learning environment}

A few of the students who commented believed that suggesting peer corrections created an unfriendly learning environment. They claimed that due to cultural constraints, they hesitated to criticise others' work unless mistakes were obvious and correcting them would not cause embarrassment to the writer. They were of the opinion that these practices could affect future mutual cooperation and that the PF activity would be time-consuming. The responses of the few students who expressed this view were "Peer feedback may cause animosity among students (F-13)", "Peer feedback sometimes causes lower confidence if the student was made fun of because of his mistakes (M-16)", "Peer feedback is time consuming (F-31)", and "It is not my habit to criticise the work of others (M-28)". There could be a background theory underlying these attitudes. Phillipson (2007: 1) argues that editors may be "too polite to offer constructive criticism to other students" or they may "go into attack-dog mode" in order to impress the instructor. Such a belief exists when students do not distinguish between criticism and critique as discussed below.

\section{Conclusion}

Depending on the attitudes of students, it can be taken that making PF a reliable strategy for enhancing students' collaboration in the writing courses in the UAE context requires consideration of technical, psychological, and cultural factors. Technically, students need adequate training on what to review in a document and how to provide both surface-level and meaning-level revisions (Paulus, 1999: 265). Learner training could be introduced as a favourable technique for empowering students with the appropriate skills necessary to act autonomously in language learning situations. It also "develops in them a habit of good writers who learn to plan, organise, draft, revise, and edit" (Charoenchang, 2013: 3). In technical writing courses, students should see samples of surface-level and content-level edited letters to identify the different aspects of feedback and the different areas they should consider when producing business documents. This increases their awareness that spelling and grammar corrections are only one part of the review process. Raising students' awareness of these traits enriches the quality of input provided while reviewing. However, we should not underestimate students' focus on grammar within the review process. It is "the organisational framework within which communication operates" (Brown, 2001: 362).

The second factor affecting student engagement in PF is mainly psychological. In the early stages of compulsory education of Arab students in the Gulf States, students used to learn mostly in a teacherdriven way. The teacher was referred to as the authority and as the "all-knowing provider of information" (Canning and Bornstein, 2001: 2). This attitude has two interpretations. Students underestimate the feedback of peers as they view the instructor as the more educated one - one from whom they receive correct input. Another possibility is that because they are not aware of the areas to be edited, they underestimate the level of input they receive. To overcome student reliance on 
teachers, Levine et al (2002) suggests combining both peer feedback and teacher feedback, at least during initial student practice of PF. Both insights complement each other and enable students to gradually trust peer feedback the more they find they are not significantly in conflict with the teacher's review. Another factor affecting student receptiveness of PF is mostly cultural. They tend to avoid criticising the work of others, considering it offensive. They believe this job is ascribed to classroom instructors rather than students. There exists a difference between criticism and critique that should be explained before exercises such as PF takes place. Criticism is often negative, looks for flaws in the writer as well as the writing, is vague and general, and often gives the impression of a fault-finding, sarcastic wit. Critique, on the other hand, is often positive, addresses only what is in the written document, is concrete and specific, and, if properly conveyed, is delivered in a kind, honest, and objective voice. Addressing these drawbacks contributes to the effectiveness of PF in writing courses with undergraduate students in UAE universities.

\section{References}

Aloud, R. (2013). Online peer feedback in writing class. In P. Davidson, M. Al-Hamly, C. Coombe, S. Troudi, \& C. Gunn (eds.), Achieving excellence through life skills education. (pp. 313-321). Dubai: TESOL Arabia Publications.

Atkine, N. (2004). The Arab mind revisited. Middle East Quarterly, 11(3): 47-55.

Azaza, M. (2013) The effect of peer editing on improving the writing mechanics of Arab learners. In P. Davidson, M. Al-Hamly, C. Coombe, S. Troudi, \& C. Gunn (eds.), Achieving excellence through life skills education. (pp. 299-312). Dubai: TESOL Arabia Publications.

Brown, H. D. (2001). Teaching by Principles: an interactive approach to language pedagogy. New York: Longman.

Brown, J. D. (2001). Using surveys in language programs. Cambridge: CUP.

Canning, C. \& Bornstein, L. (2001). Issues in the development of EFL cost recovery courses in the Arab World. Retrieved on 24 Feb. 2010 from www.eltnewsletter.com/back

Charoenchang, W. (2013). Benefits and some practical aspects of peer editing in teaching writing. Retrieved on 17 March 2013 from http://www.google.ae/url?url=http://164.115.22.25/ojs222/index.php/tuj/article/download/200/19 $6 \& r c t=j \& f r m=1 \& q=\& e s r c=s \& s a=U \& e i=2 y m y V K 7 t A Y b e 7 A a M i l H 4 B w \& v e d=0 C B M Q F j A A \& u s g=A F Q j C N E$ HLGGCdNRCKiOHw2pXZ7fuEuhm4w

Chong, K. (2010). Investigating the perception of student teachers in Hong Kong. English Language Teaching, 3 (1): 53-59.

Dörnyei, Z. (2003). Questionnaires in second language research: construction, administration, and processing. New Jersey, USA: Lawrence Erlbaum Associates.

Holliday, A. (2005). The Struggle to teach English as an international language. Oxford: OUP.

Kroll, B. (2001). Considerations for teaching an ESL/EFL writing course. In M. Celce-Murcia (Ed.), Teaching English as a second/foreign language. Heinle \& Heinle: Thomson Learning.

Levine, A., Oded, B., Connor, U., \& Asons, I. (2002). Variation in EFL-ESL peer response. TESOL EJ, 6(3), 118.

Liu, J. \& Hansen, J. (2002). Peer response in SL writing classrooms. University of Michigan Press. 
Lougheed, L. (2003). Business correspondence: a guide to everyday writing. Pearson: Longman.

Lundstrom, K. \& Baker, W. (2009). To give is better than to receive: The benefits of peer review to the reviewer's own writing. Journal of Second Language Writing 18(1): 30-43.

Paulus, T. (1999). The effect of peer and teacher feedback on student writing. Journal of Second Language Writing 8(3): 265-289.

Phillips, D. (2003). Theories of teaching and learning. In C. Randall (ed.), A Companion to the philosophy of education (pp. 232-243). Malden, MA: Blackwell.

Phillipson, M. (2007). Encouraging peer editing. In Enhanced: new media tools and resources for enhancing education. Columbia Centre for New Media Teaching and Learning.

Porto, M. (2001). Cooperate writing response groups and self-evaluation. ELT Journal, 55(1): 38-46.

Richards, J. C. \& Schmidt, R. W. (2010). Longman dictionary of language teaching and applied linguistics. England: Pearson Education Limited.

Rollinson, P. (2005). Using peer feedback in the ESL writing class. ELT Journal 59(1): 23-30

Stubbe, M. (2013). Peering into peer editing. e-Vision 11: 1-4.

Tabachnick, B. \& Fidell, L. (1996). Using multivariate statistics. New York: Harper Collins.

Tang, G. \& Tithecott, J. (1999). Peer response in ESL writing. TEFL Canada Journal, 16 (2): 20-38.

Von Glasersfeld, E. (2005). Aspects of constructivism. In C. T. Fosnot (ed.), constructivism: theory, perspectives, and practice (pp. 3-7). New York: Teachers College Press.

Wenden, A. (1999). An introduction to metacognitive knowledge and beliefs in language learning: beyond the basics. System 27: 435-441.

Yang, M.; Badger R.; \& Yu Z. (2006). A comparative study of peer and teacher feedback in a Chinese EFL writing class. Journal of Second Language Writing 15(3): 179-200. 


\section{Appendix One: Sections of a Business Letter}

\section{Model Cover Letter}

Look at the different elements of a cover letter.

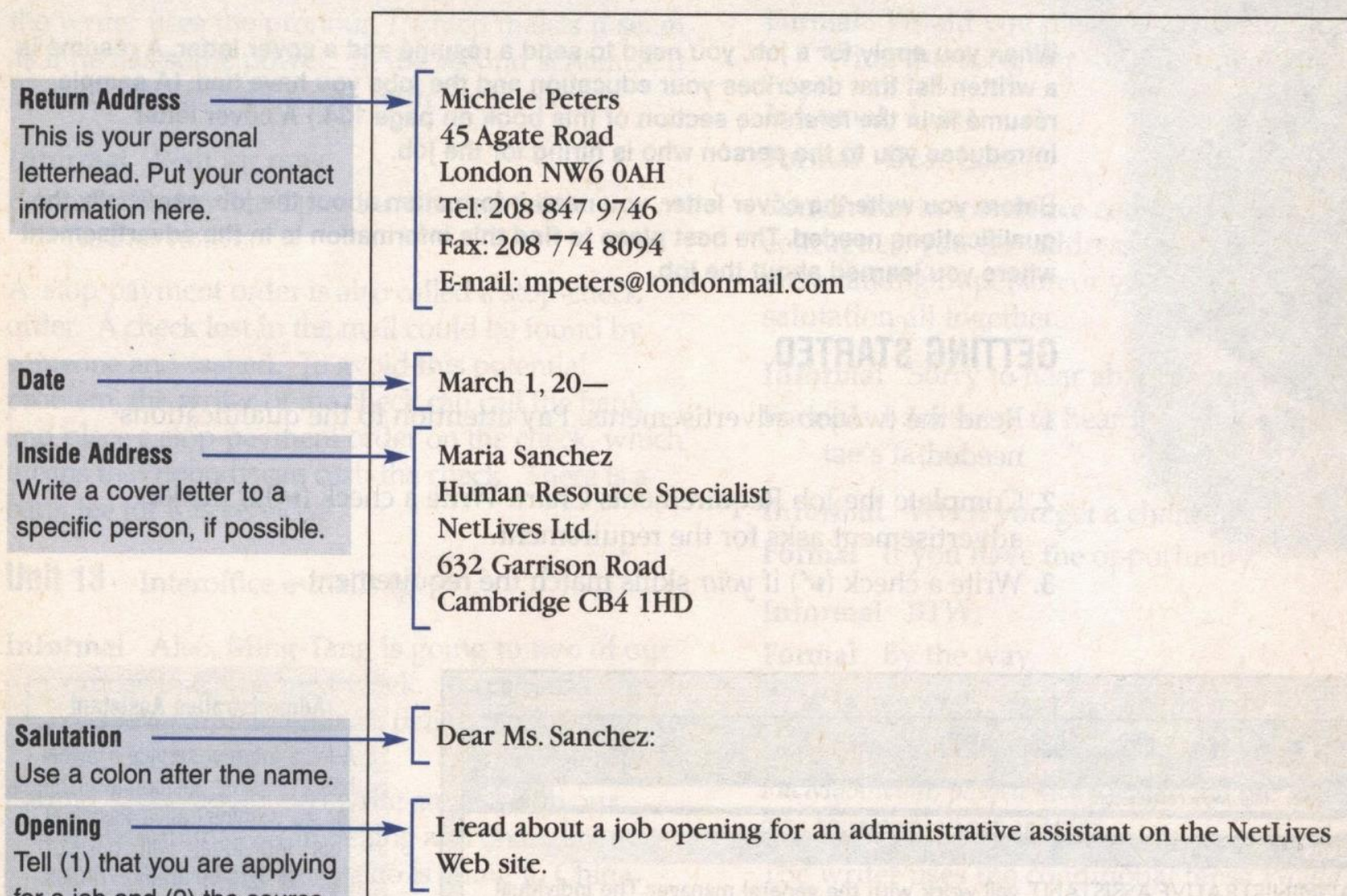

for a job and (2) the source

of your information.

Focus $\longrightarrow$ I am a recent graduate of EMP Secretarial School, and I was in the top of my

Tell why you are suited for $\quad$ Class. I am looking for a challenging work environment like that at NetLives.

the job.

Action $\longrightarrow$ I will call you next Monday to discuss my enclosed résumé.

Tell what you plan to do.

Closing $\longrightarrow$
Be positive.

Complimentary Close $\longrightarrow[$ Sincerely yours,

Signature $\longrightarrow$
Sign your name. $[$ Michele Peters

Typed Name $\longrightarrow[$ Michele Peters

Enclosure

Add this if you are sending

something with the letter. 


\section{Appendix Two: Samples of Edited Documents with Minor Changes}

\begin{tabular}{l} 
To: secy6433@JobsunLtd.com \\
Subject: Secretarial Positioning \\
\hline Dear Recruiter, \\
I am responding for the secretarial vacancy posted on August 16 in your Web site. \\
I have been an executive secretary since five years. I also have trained other \\
secretaryes how to use word processing and accounting software I type over \\
90 wpm, and I am very organized. I have attached my résumé to this e-mail. \\
I will e-mail you next week to follow up on my apply. I look forward to hear from \\
you soon. \\
Sincere yours, \\
Liu Shia
\end{tabular}

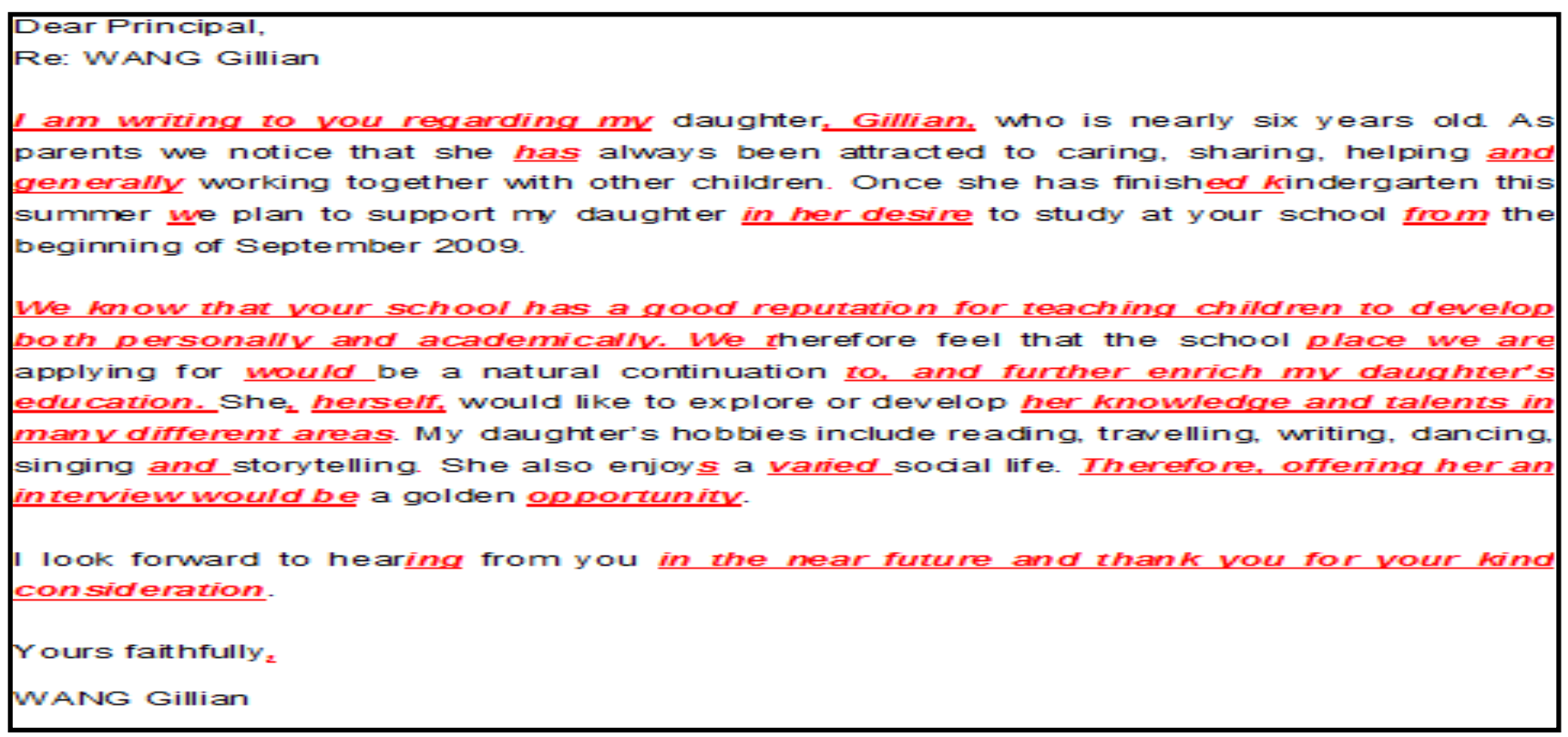

The purpose of this study was to replicate and extend the research of Siegle and McCoach (2003) by investigating the common characteristics of gifted achievers and gifted underachievers in China. The sample consisted of third-culture kids from Grades $6-$ 12 at SMIC Private School, a private international English-speaking school in Shanghai. The School Attitude Assessment Survey-Revised (SAAS-R) instrument was given to 27 underachievers and a comparison group of 69 honour roll students. The SAAS-R contained five subscales: academic self-perceptions, attitudes toward teachers, attitudes toward school, goal valuation, and motivation/self-regulation. The studvtested if Sieg/e and McCoach's finding that the goal valuation and motivation/self-regulation subscales served as the best predictors of classification would ho/d true Results revealed that the means of underachieving students and the comparison group differed on all five subscales. The subscales of academic self-perception and attitudes toward school showed the greatest difference between the two groups. Academic self-perception was the best predictor of group classification for gifted achievers and gifted underachievers. 


\section{Appendix Three: The Questionnaire}

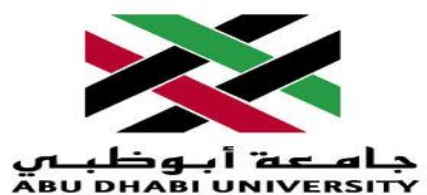

Student Name (Optional):

Nationality:

Course of Study:

Age:

\section{Peer Feedback for Peer Collaboration and Sharing}

Please read the items below and tick $(\mathrm{V})$ the degree that best matches your view. Then add any input you have about the topic in the last question.

\begin{tabular}{|c|c|c|c|c|c|c|}
\hline NO & Items & $\begin{array}{l}\text { Strongly } \\
\text { agree }\end{array}$ & Agree & Not sure & Disagree & $\begin{array}{l}\text { Strongly } \\
\text { disagree }\end{array}$ \\
\hline 1 & $\begin{array}{l}\text { I think peer feedback is helpful for } \\
\text { improving my writing skill. }\end{array}$ & & & & & \\
\hline 2 & $\begin{array}{l}\text { I trust the feedback I get from other } \\
\text { classmates. }\end{array}$ & & & & & \\
\hline 3 & $\begin{array}{l}\text { While reviewing, I focus on surface spelling } \\
\text { and grammar mistakes. }\end{array}$ & & & & & \\
\hline 4 & $\begin{array}{l}\text { The teacher should provide rubrics to } \\
\text { follow before reviewing any writing. }\end{array}$ & & & & & \\
\hline 5 & $\begin{array}{l}\text { My feedback varies based on my interest } \\
\text { and familiarity with the topic. }\end{array}$ & & & & & \\
\hline 6 & $\begin{array}{l}\text { Peer feedback enhances my } \\
\text { independence, autonomy, and self- } \\
\text { confidence. }\end{array}$ & & & & & \\
\hline 7 & $\begin{array}{l}\text { What other advantages / disadvantages } \\
1 . \\
\text { 2. } \\
\text { 3. } \\
\text { 4. }\end{array}$ & f peer ed & ng do yc & see? & & \\
\hline
\end{tabular}

